\title{
Fatigue Reliability Assessment of Orthotropic Bridge Decks under Stochastic Truck Loading
}

\author{
Yang Liu, ${ }^{1}$ Xinhui Xiao, ${ }^{1}$ Naiwei Lu, ${ }^{1,2}$ and Yang Deng ${ }^{1}$ \\ ${ }^{1}$ School of Civil Engineering and Architecture, Changsha University of Science and Technology, Changsha 410114, China \\ ${ }^{2}$ Institute for Risk and Reliability, Leibniz Universität Hannover, 31509 Hannover, Germany \\ Correspondence should be addressed to Naiwei Lu; lunaiweide@163.com
}

Received 24 August 2016; Accepted 31 October 2016

Academic Editor: Tai Thai

Copyright (C) 2016 Yang Liu et al. This is an open access article distributed under the Creative Commons Attribution License, which permits unrestricted use, distribution, and reproduction in any medium, provided the original work is properly cited.

\begin{abstract}
A steady traffic growth has posed a threat to the fatigue safety of existing bridges. Uncertainties in traffic flows add to the challenge of an accurate fatigue safety assessment. This article utilizes a stochastic traffic load model to evaluate the fatigue reliability of orthotropic steel bridge decks. The traffic load model is simulated by site-specific weigh-in-motion measurements. A response surface method is presented to solve the time-consuming problem caused by hotspot stress simulations in the finite element model. Applications of the stochastic traffic load model for probabilistic modeling and fatigue reliability assessment are demonstrated in the case study of a steel box-girder bridge. Numerical results indicate that the growth rate of the gross vehicle weight leads to a rapid decrease of the fatigue reliability in comparison to the traffic volume growth. Even though the traffic volume growth is rapid, the control of overloaded trucks in comparison to the traffic volume is an effective way to ensure the fatigue safety of the steel bridges.
\end{abstract}

\section{Introduction}

Fatigue damage accumulation is one of the crucial issues leading to collapse of most steel bridges. According to a study conducted by the ASCE committee [1], approximately 80$90 \%$ of steel bridge failures are caused by fatigue and fracture issues. In general, a fatigue-critical component of a steel bridge is designed with enough fatigue resistance and fatigue life against the cyclic vehicular load [2-4]. However, a steady increase in both the traffic volume and gross vehicle weight (GVW), due to rapid growth and expansion of developments in intercity and interstate transportation, has posed a threat to the fatigue safety of existing bridges $[5,6]$. Uncertainties in traffic flows lead to another challenge of an accurate fatigue damage evaluation. The fatigue-critical components of most highway steel bridges are welded joints in the deck plates, where strain sensors are difficult to be fixed. Consequently, fatigue reliability assessment of orthotropic bridge decks with consideration of real traffic loads is still a challenge.

A critical step for fatigue reliability assessment of bridges is the probabilistic modeling of fatigue stress ranges. In this regard, most researchers utilized strain measurements in structural health monitoring (SHM) system to conduct the statistical analysis [7-9]. However, application of the SHM system is limited by its expensive cost and limited specified objectives. With the development of sensor technologies, the site-specific weigh-in-motion (WIM) system, which is initially developed for traffic management, has been widely used for statistical analysis of traffic loads [10]. Therefore, integration of site-specific WIM measurements and the finite element (FE) method becomes a practical approach for fatigue reliability assessment of in-service bridges. Numerous analytical approaches have been presented on this topic. For instance, Wang et al. [11] developed a computational framework to evaluate the fatigue damage increment of the steel box-girder bridge by combining FE computations and SHM data. Guo et al. [12] utilized a multiscale probabilistic FE model to evaluate the fatigue reliability of an orthotropic steel bridge deck. Zhang et al. [13] utilized an equivalent orthotropic material approach to simulate the dynamic load in the FE model. Ye et al. [14] studied the sensitivity of the element size and the element type in calculating the structural 
stress under the vehicle load. Zhang and $\mathrm{Au}$ [15] presented an advanced probabilistic load model to simulate the truck-load on a bridge based on WIM measurements and then evaluated the fatigue reliability and the remaining service life of the bridge. As elaborated above, integrating the monitored traffic data and the FE-based numerical simulation is an effective approach for fatigue reliability assessment of steel bridges.

Modeling traffic load is a critical procedure for integrating WIM measurements and the FE method for fatigue reliability assessment of steel bridges. The typical fatigue truck-load model specified in national design specifications and several advanced truck-load models are conventional in the opening literatures [16]. In this regard, Laman and Nowak [17] developed a 3-axle truck-load model based on WIM measurements. Chotickai and Bowman [18] developed a 4-axle truck-load model and indicated that the AASHTO truck-load model can be notably overestimated in short-span bridges. Lan et al. [19] combined the traffic load spectrum and the traffic volume forecast for fatigue damage evolution of bridges. Chen et al. [20] utilized actual traffic loads to assess the fatigue performance of an arch bridge. In addition to the configuration of the truck illustrated above, the dynamic effect due to vehicle-bridge interaction will also affect the fatigue stress spectrum [21]. Since the traffic parameters (e.g., vehicle types, driving speeds, vehicle spacing, and GVWs) are random in nature, the statistical information of all trucks is not included in the aforementioned truck-load models. Therefore, a stochastic traffic load model is necessary for an accurate estimation of the fatigue damage accumulation. However, to the best of the authors' knowledge, most of the relative research efforts with respect to the stochastic traffic load model have focused on the vehicle-bridge interaction analysis $[22,23]$, while research on application of stochastic traffic load model to for fatigue reliability assessment of steel bridges is relatively insufficient.

This study aims at developing a stochastic traffic load model based on site-specific WIM measurements to evaluate fatigue reliability of orthotropic steel bridge decks. A computational framework integrating the FE-based deterministic hotspot stress simulation and probabilistic modeling of stress ranges is presented. In the case study, a steel box-girder bridge is chosen as a prototype to demonstrate the effectiveness of the application of stochastic fatigue truck load mode. Influence of the parameters in the stochastic truck-load model on the fatigue reliability index is investigated.

\section{Stochastic Traffic Load Model}

In general, a fatigue truck-load model, which contains deterministic configurations and axle loads, is used to represent the site-specific traffic loading. The fatigue truck-load model is usually evaluated through the real traffic load spectrum based on the equivalent fatigue damage accumulation criterion. However, due to the deterministic configuration and axle load, the fatigue load model is unappropriated to be used for probabilistic modeling of fatigue damage accumulation. Herein, a stochastic traffic load model based on WIM measurements is present to simulate the real traffic flow and the subsequent fatigue reliability assessment of steel bridges.
TABLE 1: Overview of the WIM measurement.

\begin{tabular}{lc}
\hline Items & Values \\
\hline Time period & May 1, 2013, to April 30, 2015 \\
Number of recording days & 729 \\
Average daily truck traffic & 2145 \\
Maximum GVW $(\mathrm{kN})$ & 1,645 \\
Number of overloaded trucks & 12,252 \\
\hline
\end{tabular}

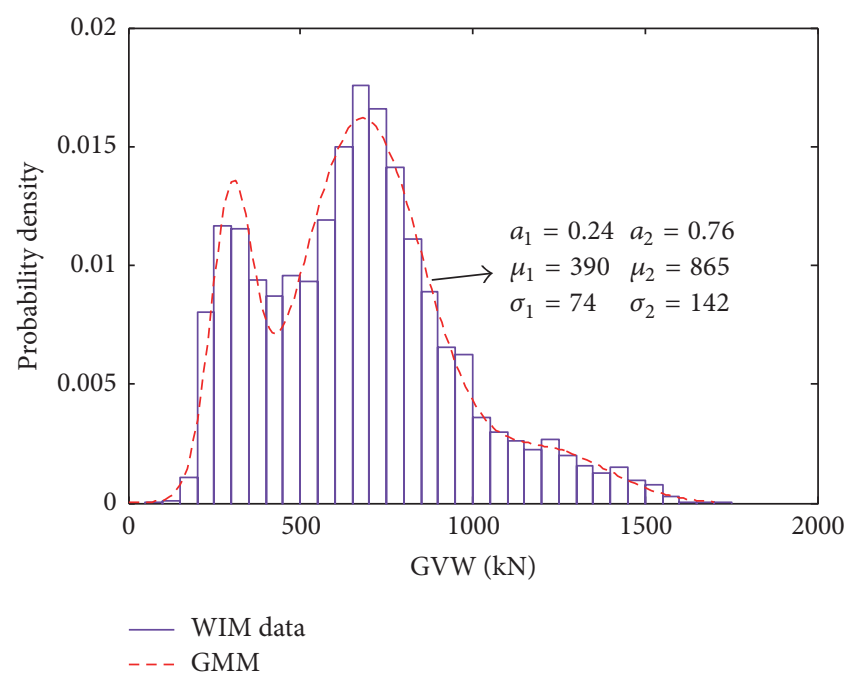

FIgURE 1: Histogram and PDF of the GVW of the 6-axle truck.

2.1. WIM Measurements. The traffic measurement utilized in the present study stems from a WIM system of a highway bridge at Sichuan, China. More information of the WIM system can be found by Liu et al. [24] and Lu et al. [25]. Filtering processes were conducted to eliminate the invalid data. The criteria of identifying the invalid data are (1) the individual GVW is less than $30 \mathrm{kN}$; (2) the axle weight is larger than $400 \mathrm{kN}$ or less than $5 \mathrm{kN}$; and (3) the axle spacing is greater than $20 \mathrm{~m}$. Overview of the effective data is shown in Table 1.

With the WIM measurements, the first step of the statistical analysis is the vehicle type classification. According to the vehicle configuration, all vehicles are classified into 6 types as shown in Table 2 . It is observed that about $60 \%$ of the filtered vehicles are 2 -axle trucks and light cars. In addition, about $90 \%$ of heavy trucks are driving in the slow traffic lane, while more light trucks are prone to be driving in the fast traffic lane. This phenomenon of the traffic composition will impact the fatigue reliability of steel bridges.

Taking the 6-axle truck as an example, the histogram and probability density function (PDF) of the gross vehicle weight are shown in Figure 1 , where $a_{i}, \mu_{i}$, and $\sigma_{i}$ are parameters in the Gaussian Mixture Model (GMM). The linear regression functions between the individual axle weight and the GVW 
TABLE 2: Vehicle classifications.

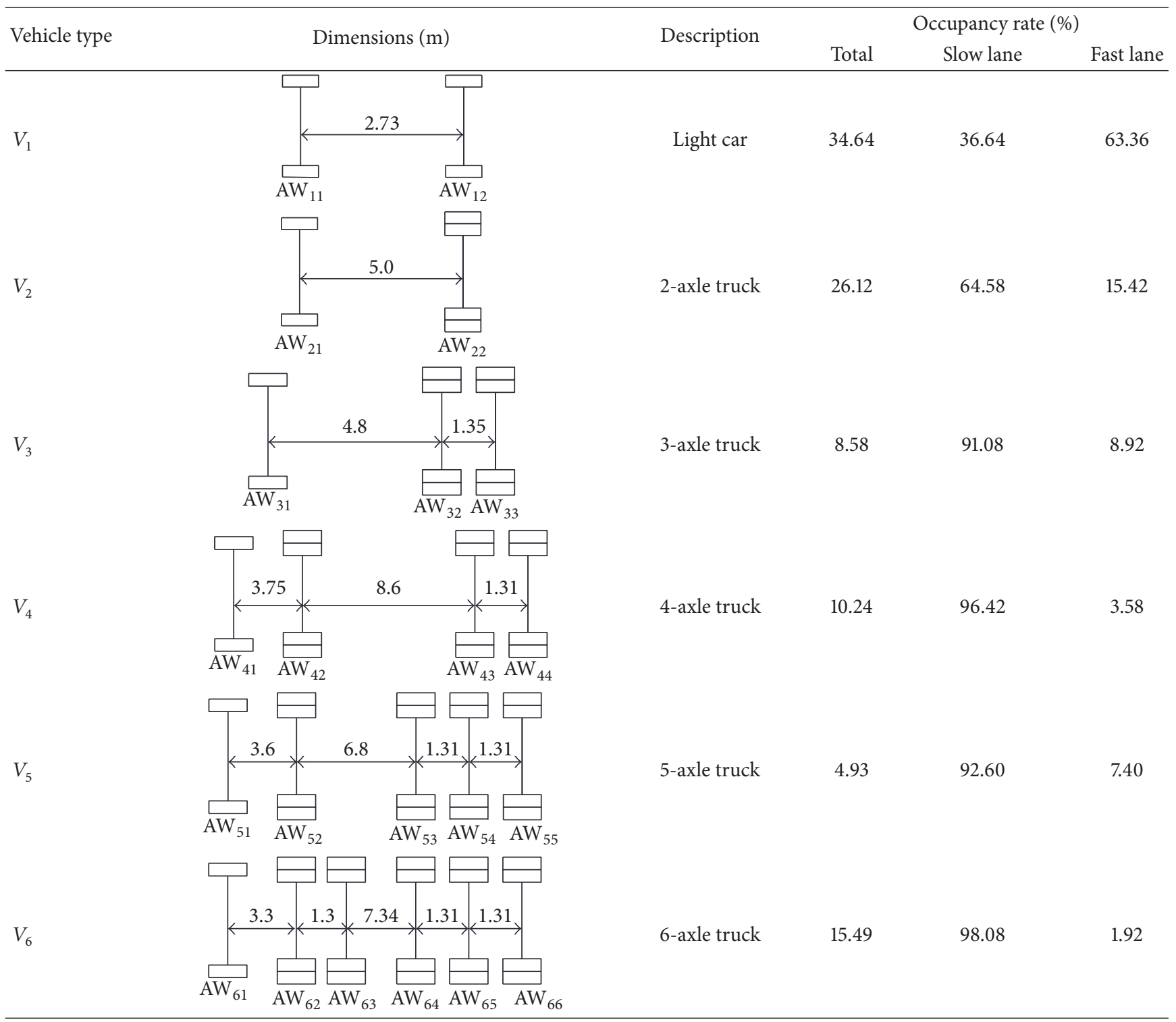

are shown in Figure 2. It is assumed that the individual axle weights for the tandem and tridem axles are the same.

2.2. Stochastic Traffic Load Simulation. In general, a stochastic traffic model is defined by vehicle types, vehicle speeds, vehicle gaps, driving lines, and vehicle weights [26]. For the purpose of fatigue analysis in the present study, the stochastic traffic model was improved by considering the parameters with significant contribution to structural fatigue damage. The effective stress influence line of orthotropic steel decks is usually within two diaphragms that are roughly $3.2 \mathrm{~m}$ [2729], which will be shown in the case study. Therefore, the vehicle type and the driving lane as well as the axle weight were chosen for modeling the stochastic truck-load. There are mainly two reasons for the chosen parameters. First, the vehicle spacing was excluded, because the vehicle gap between two trucks in the same traffic lane was usually larger than the effective stress influence lane. In addition, the consideration of the vehicle spacing will increase the computational effort in the time intergradation of the transient analysis. Second, the axle spacing as well as driving lane was considered in the vehicle configuration, because the distances of both axle spacing and two traffic lanes were close to the effective stress influence line. Finally, the driving speed was considered as a constant for considering the dynamic effect. In addition, the vehicles with a GVW less than $30 \mathrm{kN}$ were ignored, since these vehicles have little contribution to the fatigue damage. As elaborated above, the stochastic traffic load model was formed by three random variables including the vehicle type, the axle weights, and the driving lane.

With the PDF of the three parameters illustrated above, the stochastic traffic load model can be established by the Monte Carlo simulation. A linear growth factor of average daily truck traffic (ADTT) volume was assumed as $0.5 \%$. The 


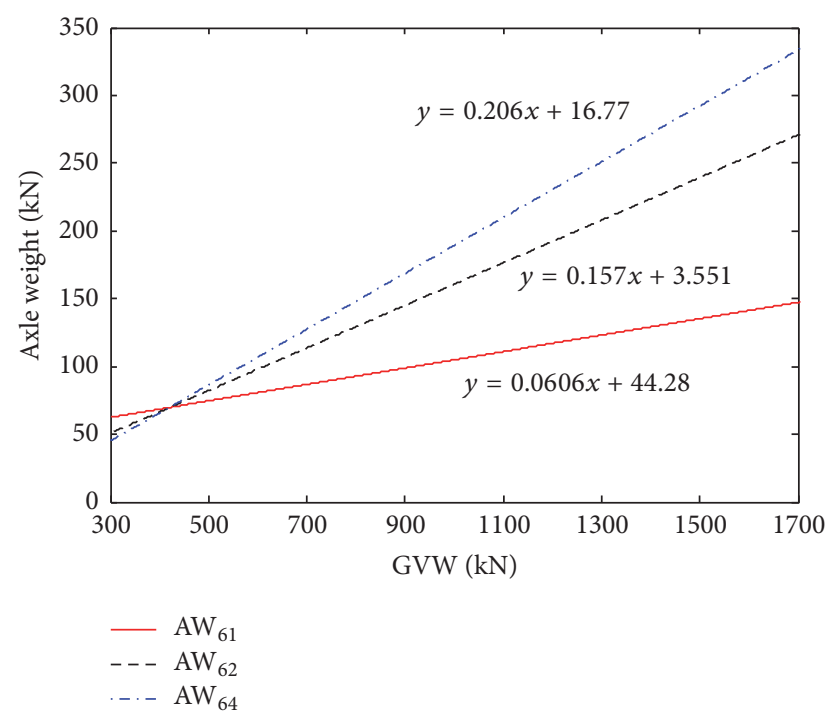

FIGURE 2: Fitted functions of axle weight distributions of the 6-axle truck.

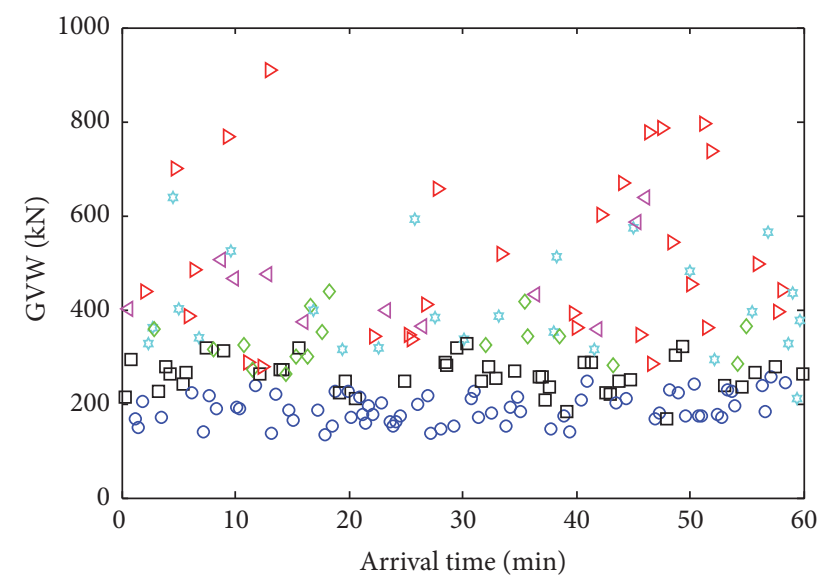

FIGURE 3: Simulated stochastic traffic load model.

simulated stochastic traffic load model in $60 \mathrm{~min}$ is shown in Figure 3. Note that the individual GVW is used instead of the axle weight for the convenience of expression.

As shown in Figure 3, each dot refers to a truck specified by a different mark style, $x$-axis shows the arrival time, and $y$-axis shows the individual GVW. It is observed that every individual truck is different from the other, but they follow a relative probability distribution. Therefore, the stochastic fatigue truck-load model contains the statistics of the WIM measurement.

\section{Methodology}

3.1. Theoretical Basis. Since each passing vehicle will induce fatigue stress blocks in bridge decks, the fatigue stress blocks are time-variant and amplitude-variant. There are two aspects that need farther consideration for the truck-induced fatigue damage accumulation. First, $S-N$ curve should be determined with the consideration of low-stress and high-cycle properties of truck-induced fatigue stress blocks. Second, categories of the welded joints should be included in the $S-N$ curve. Eurocode 3 specification [30] was utilized in this study because of the thorough consideration of the properties illustrated above. The general form of the $S-N$ curve in Eurocode 3 specification is

$$
\begin{array}{ll}
\Delta \sigma_{R}^{3} N_{R}=K_{C} & \left(\Delta \sigma_{R} \geq \Delta \sigma_{D}\right), \\
\Delta \sigma_{R}^{5} N_{R}=K_{D} & \left(\Delta \sigma_{L}<\Delta \sigma_{R} \leq \Delta \sigma_{D}\right),
\end{array}
$$

where $\Delta \sigma_{R}$ is the fatigue stress range, $N_{R}$ is the number of stress cycles, $\Delta \sigma_{D}$ and $\Delta \sigma_{L}$ are the constraint amplitude fatigue threshold and the variable amplitude fatigue threshold, respectively, and $K_{C}$ and $K_{D}$ are the detail coefficients of stress ranges that are higher and lower than $\Delta \sigma_{D}$, respectively.

It is worth noting that $S-N$ curves can only be used for constant-amplitude fatigue blocks. However, the truckinduced fatigue stresses ranges are amplitude-variant due to the randomness of the traffic loads. Thus, an equivalent stress range method is utilized in the present study based on Miner's fatigue damage accumulation theory [31], which is written as

$$
D=\sum_{\Delta \sigma_{i} \geq \sigma_{D}} \frac{n_{i} \Delta \sigma_{i}^{3}}{K_{C}}+\sum_{\Delta \sigma_{j}<\sigma_{D}} \frac{n_{j} \Delta \sigma_{j}^{5}}{K_{D}}=\frac{N_{\mathrm{eq}} \Delta \sigma_{\mathrm{re}}^{5}}{K_{\mathrm{D}}},
$$

where $D$ is the fatigue damage accumulation; $\Delta \sigma_{i}$ and $\Delta \sigma_{j}$ are fatigue stress ranges that are greater and less than $\Delta \sigma_{D}$, respectively; $n_{i}$ and $n_{j}$ are the number of stress cycles for $\Delta \sigma_{i}$ and $\Delta \sigma_{j}$, respectively; and $\Delta \sigma_{\text {re }}$ and $N_{\text {eq }}$ are the equivalent fatigue stress range and the equivalent number of stress cycles, respectively. Note that $N_{\mathrm{eq}}$ under an individual truckload is assumed to be equal to the number of the axles. According to (2), $\Delta \sigma_{\text {re }}$ under an individual truck-load can be written as

$$
\begin{aligned}
& \Delta \sigma_{\text {re }}^{5} \\
& =\frac{\sum_{\Delta \sigma_{i} \geq \Delta \sigma_{D}}\left(n_{i} \Delta \sigma_{i}^{3} / K_{C}\right)+\sum_{\Delta \sigma_{j}<\Delta \sigma_{D}}\left(n_{j} \Delta \sigma_{j}^{5} / K_{D}\right)}{N_{\text {eq }} / K_{D}} .
\end{aligned}
$$

The stress spectrum under daily traffic flow can be formed by repeating the analysis of each truck passage. In addition to the fatigue stress spectrum, transverse distribution factor of truck on the bridge deck and the traffic volume will affect the fatigue damage accumulation. During the longterm service period of a bridge, the ADTT and individual GVW will increase due to the global economic development. Taking into account all of the above parameters, the limit state function (LSF) of fatigue damage accumulation is written as

$$
\begin{aligned}
& g_{n}(\mathbf{X})=D_{\Delta}-\sum_{t=1}^{n} D_{t}(X)=D_{\Delta} \\
& -365 N_{\mathrm{ADTT}} \Delta \sigma_{\mathrm{re}}^{5} w \sum_{i=1}^{6} P_{(i)} N_{\mathrm{eq}(i)} \\
& \cdot \sum_{t=1}^{n} \frac{\left[1+(t-1) R_{\mathrm{ADTT}}\right]\left[1+(t-1) R_{\mathrm{GVW}}\right]^{5}}{K_{D}},
\end{aligned}
$$




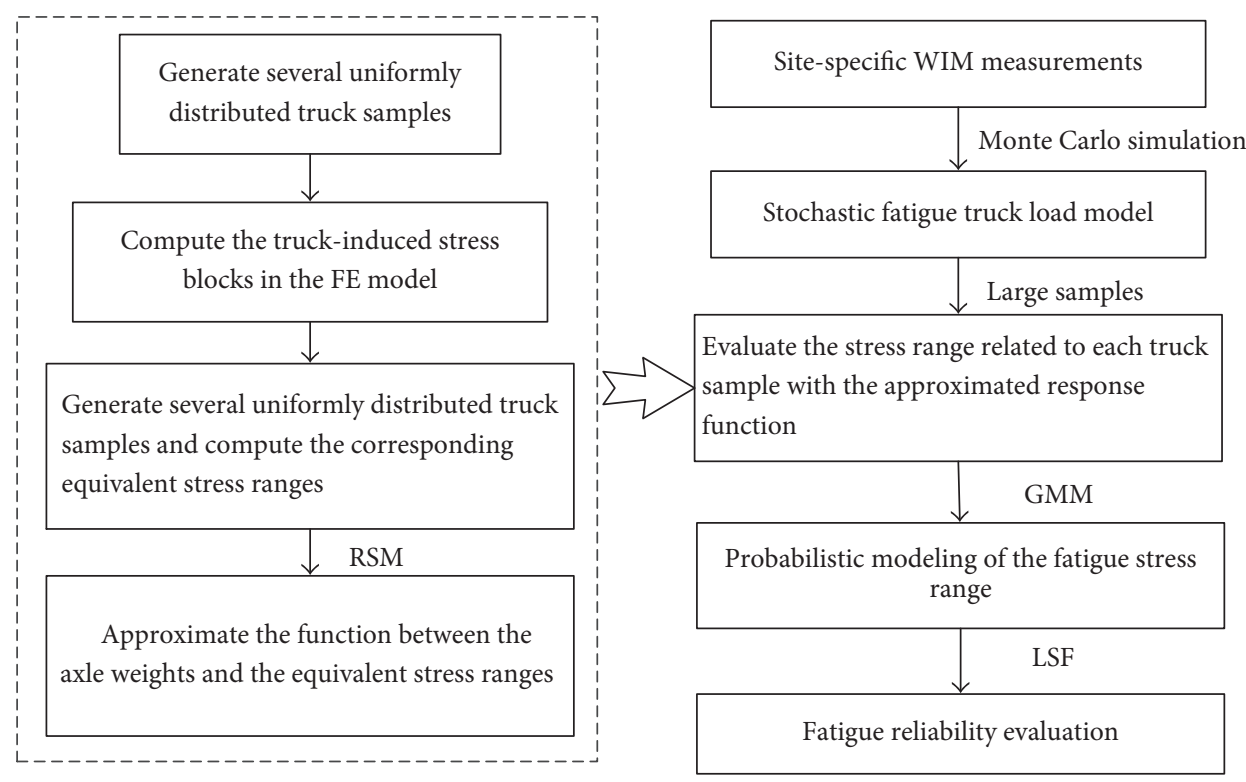

FIgURE 4: Flowchart of the proposed computational framework.

where $n$ (in years) is the service period of a bridge, $w$ is the transverse distribution factor of a truck diving in a traffic lane, $N_{\text {ADTT }}$ is the number of the ADTT, $P_{(i)}$ is the proportion of the $i$ th vehicle type in the database, $R_{\mathrm{ADTT}}$ is a linear annual growth rate of the ADTT, and $R_{\mathrm{GVW}}$ is a linear annual growth rate of the GVW.

3.2. The Proposed Computational Framework. The kernel procedure connecting the aforementioned stochastic traffic load model with the fatigue limit state function is the probabilistic modeling of the fatigue stress range. There are three steps for the traditional approaches to evaluate the fatigue damage accumulation [32]. First, simulate the stress history of a fatigue-critical point under a moving truck-load. Second, convert the history into stress blocks by utilizing the rain-flow method. Finically, the individual fatigue damage is evaluated by $S-N$ curve and accumulated by Miner's rule. However, this framework is inappropriate for the stochastic truck-load, because of the time-consuming problem caused by numerous repeated computer runs. Therefore, a computational framework is presented for the probabilistic modeling.

In order to solve the time-confusing problem, a response surface methodology (RSM), which is conventionally utilized as a metamodel, is utilized herein to substitute the FE model. The response surface functions describing the relationship between the vehicle axle weight and the equivalent stress range were approximated. A flowchart of describing the entire procedure is summarized in Figure 4. There are two main procedures including approximating response surface functions and the probabilistic modeling of equivalent stress ranges.

3.2.1. Approximating Response Surface Functions. Since each truck passage will pose several stress blocks due to the multiaxle and dynamic effects, the relationship between the axle load and the equivalent stress ranges is complex. The integration of uniform design (UD) and RSM, which is commonly used for structural reliability evaluation [33], is utilized herein to approximate the implicit function between the axle weights and the equivalent stress ranges. Since there are 6 types of vehicles, a total number of 6 functions are necessary for the entire trucks. First of all, the upper and lower bound of the GVW should be determined and then generate several uniformly distributed samples in the defined region via a uniform design (UD) approach [34, 35]. Subsequently, conduct the finite element analysis to estimate the stress histories under individual truck passage, and then convert the stress histories into stress blocks via the rain-flow method. Consequently, the variant-amplitude stress blocks are converted into constant-amplitude stress blocks. Herein, the input and output samples are obtained. The response surface function with respect to a vehicle type can be approximated with the above UD samples.

3.2.2. Probabilistic Modeling Based on GMM. With the approximated response surface function, the probabilistic modeling can be carried out efficiently. The purpose of the probabilistic modeling is to establish a probability model of the equivalent stress range. In practice, the PDF of the equivalent stress range is complex and may not be well fitted by a typical Gaussian or Lognormal distribution function. In order to deal with this problem, a Gaussian Mixture Model (GMM) [35] is utilized in the present study. The GMM is part of the finite mixture distributions that are commonly utilized for modeling complex probability distributions and enable the statistical modeling of random variables with multimodal behavior. A PDF of a finite mixture distribution with independent scalars is written as

$$
f(y, a, \theta)=\sum a_{i} f_{i}\left(y \mid \theta_{i}\right)
$$




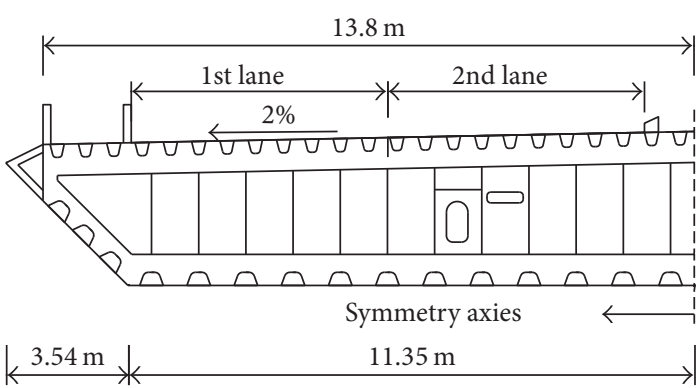

(a)

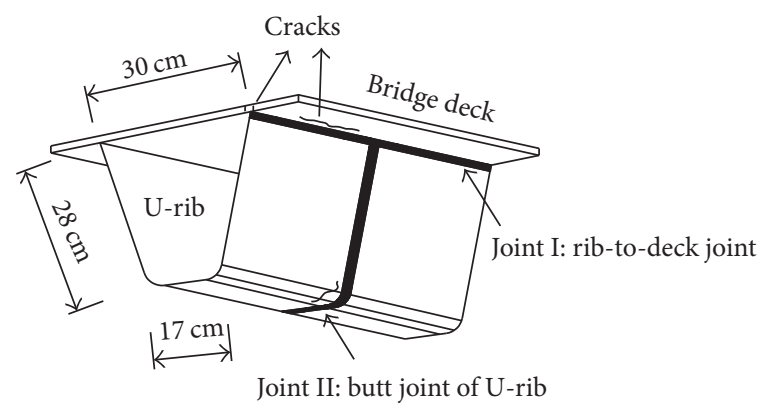

(b)

FIgURE 5: Dimensions of the steel box-girder: (a) half cross section and (b) U-rib.

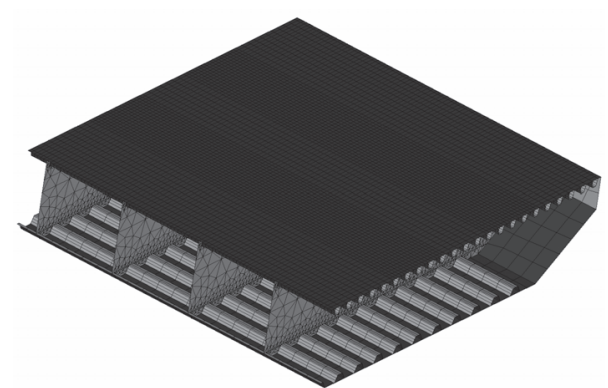

FIGURE 6: Finite element model of a half-segmental steel box-girder.

where $f(y, a, \theta)$ is a predictive mixture density function and $f\left(y \mid \theta_{i}\right)$ is a given parametric family of predictive component densities, $a_{i}$ is the $i$ th component weight, and $\theta_{i}$ is a component parameter. For instance, taking the Gaussian function as the given predictive component density, the GMM is written as

$$
f(y, a, \theta)=\sum a_{i} \frac{1}{\sqrt{2 \pi}} \exp \left\{-\frac{1}{2} \frac{\left(y-\mu_{i}\right)}{\sigma_{i}^{2}}\right\},
$$

where $\mu_{i}$ and $\sigma_{i}$ are the mean value and standard deviation of the $i$ th mixture parameter. The GMM provide a connection between the PDFs of GVWs and the equivalent stress range.

\section{Case Study}

A segmental steel box-girder bridge is utilized herein as a prototype to demonstrate the application of the site-specific stochastic fatigue truck-load model for fatigue reliability assessment. Influence of the parameters in the stochastic traffic load model on the reliability index is discussed.

4.1. Prototype Bridge. The prototype bridge is a steel boxgirder bridge at Sichuan, China. There are four traffic lanes in the opposite directions. Dimensions of a half cross section and a U-rib are shown in Figure 5.

A finite element model shown in Figure 6 was built on a commercial program ANSYS. In the finite element model, the longitudinal, transvers, and vertical lengths are $12.8 \mathrm{~m}$, $15 \mathrm{~m}$, and $3 \mathrm{~m}$, respectively. The deck and U-ribs were meshed
TABLE 3: Statistics of random variables.

\begin{tabular}{|c|c|c|c|c|}
\hline Variables & $\begin{array}{l}\text { Mean } \\
\text { value }\end{array}$ & $\mathrm{COV}$ & Distribution & Description \\
\hline$D_{\Delta}$ & 1.0 & 0.3 & Lognormal & $\begin{array}{c}\text { Critical fatigue } \\
\text { damage }\end{array}$ \\
\hline$K_{D}$ & $3.47 \times 10^{14}$ & 0.34 & Lognormal & $\begin{array}{l}\text { Fatigue } \\
\text { strength } \\
\text { coefficient }\end{array}$ \\
\hline$w$ & 0.8 & 1 & Normal & $\begin{array}{c}\text { Transverse } \\
\text { distribution } \\
\text { factor }\end{array}$ \\
\hline
\end{tabular}

TABLE 4: Parameters of $S-N$ curves in Eurocode 3 specification.

\begin{tabular}{lccccc}
\hline Welded joint & $\begin{array}{c}\text { Classification } \\
(\mathrm{MPa})\end{array}$ & $\begin{array}{c}\Delta \sigma_{D} \\
(\mathrm{MPa})\end{array}$ & $\begin{array}{c}\Delta \sigma_{L} \\
(\mathrm{MPa})\end{array}$ & $K_{\mathrm{C}}$ & $K_{D}$ \\
\hline Deck-to-rib & 50 & 37 & 20 & $\begin{array}{c}2.50 \times \\
10^{11}\end{array}$ & $\begin{array}{c}7.16 \times \\
10^{14}\end{array}$ \\
$\begin{array}{l}\text { Butt joint of } \\
\text { U-rib }\end{array}$ & 71 & 52 & 29 & $\begin{array}{c}3.47 \times \\
10^{11}\end{array}$ & $\begin{array}{c}19.00 \times \\
10^{14}\end{array}$ \\
\hline
\end{tabular}

with quadrilateral elements, while the longitudinal stiffening plates, the diaphragm plates, and the web plates were meshed with triangular elements.

4.2. Statistics of Variables. Probabilistic modeling of these variables shown in (3) is a critical task to conduct the subsequent reliability evaluation. The critical fatigue damage index and the fatigue strength coefficient in terms of resistance are assumed to follow lognormal distributions [36]. The transverse distribution factor of the truck axle is assumed to follow normal distribution with the mean value of 0.3 and coefficient of variation (COV) of 1 . Based on the above assumption, the statistics of the variables in the LSF are shown in Table 3. Taking the rib-to-deck joint and butt joint of Uribs as examples, the determined parameters specified in the Eurocode 3 specification are show in Table 4.

In addition to these parameters, the equivalent stress range, $\Delta \sigma_{\text {re }}$, and the corresponding number of cycles, $N_{\text {eq }}$, caused by the actual traffic flows, mostly affect the bridge fatigue damage accumulation. Their probabilistic model 


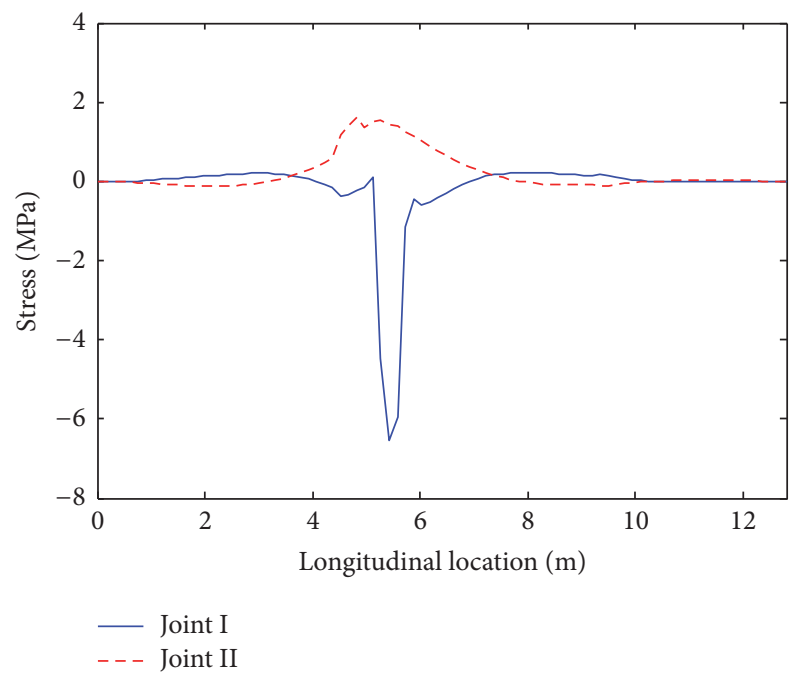

FIgURE 7: Stress influence lines of the welded joints.

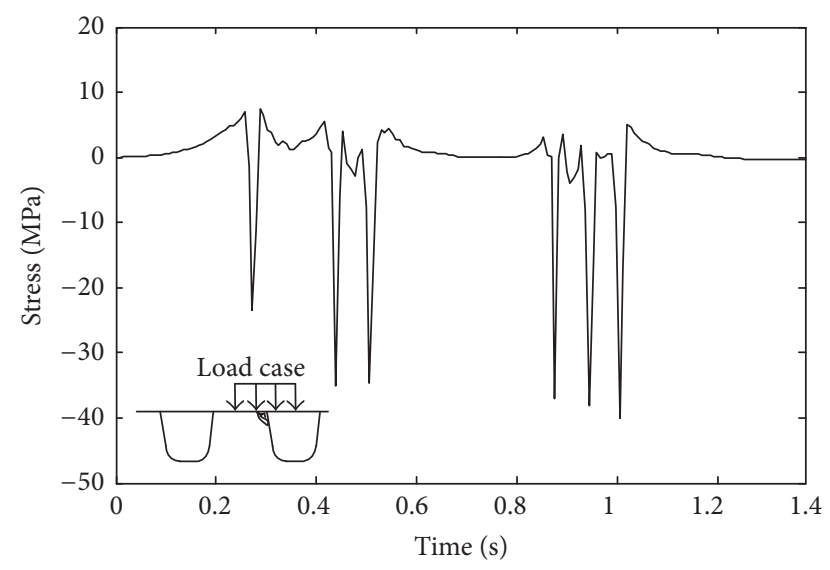

FIGURE 8: Stress-time curves of welded details of the steel box-girder under $V_{6}$ load.

under stochastic fatigue truck passage will be discussed separately below.

4.3. Probabilistic Modeling. In order to observe the character of the truck-induced stress history, stress influence lines of the two welded joints were computed. Figure 7 plots the static stress influence lines of the welded joints in the segmental model. It is observed that the effective stress influence line is mostly confined to the region of two-diaphragm plate. This has demonstrated the significance of the axle spacing and the vehicle configuration in the stochastic truck-load model.

In order to consider the pavement effect that was not considered in the finite element model the axle weights were simulated with a vertical uniformly distributed load that extends to the steel deck with $45^{\circ}$. For instance, the thickness of pavement is $6.7 \mathrm{~cm}$, and the load area of the back wheel is $60 \mathrm{~cm} \times 20 \mathrm{~cm}$; then the revised load area is $73.4 \mathrm{~cm} \times 33.4 \mathrm{~cm}$. Taking the maximum and minimum vehicle weight of 6 -axle trucks as an example, the stress histories of the rib-to-deck joint are shown in Figure 8.

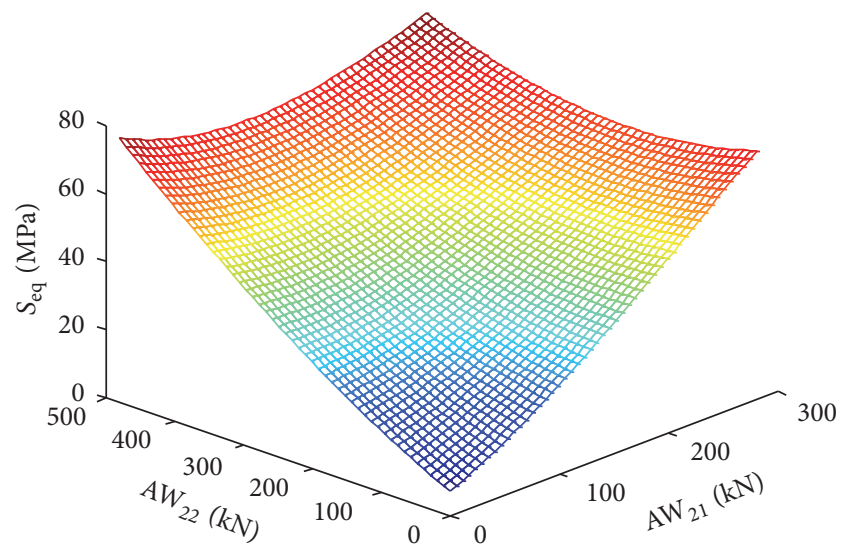

FIGURE 9: Response surface of the 2-axle truck.

As observed from Figure 8, the stress amplitude is variant and the peak value appears as the truck wheels move to the welded joint. Taking the 2 -axle truck as example to illustrate the application of the framework, the total number of the training data is 20. After 20 times of computer runs the equivalent stress ranges are obtained and the response surface function is established as shown in Figure 9. It is worth noting that the 6 -axle truck needs 30 training samples, since there are 3 random axle load variables in the 6-axle truck.

As shown in Figure 9, the design samples are uniform in the design space and the approximated response surface is closed to the training data. In addition, the approximated function is nonlinear, and the response surface is appropriate for the approximation. With the approximated SVR function of each type of vehicle, the fatigue stress ranges of the welded detail of the rib-to-deck under the daily traffic flow can be calculated and the corresponding probability density can be approximated by the GMM approach. The daily number of stress cycles can be obtained and the probability density can be calculated according to the probability density of ADTT. Note that the number of stress cycles is equivalent to the number of vehicle axles. The probability densities of the number of stress cycles in 100 days are shown in Figure 10.

It can be found from Figure 10 that there are 2 peaks in the probability density of the stress range which is well fitted by the GMM compared with the normal distribution model. Furthermore, the fatigue stress ranges spectrum contains more high-stress cycles. The probability density of the number of daily cycles is approximated with normal distribution. As elaborated above, the probability model of the stress range and the number of cycles established above provide a basis for the subsequent fatigue reliability evaluation.

4.4. Fatigue Reliability Evaluation. With the probabilistic model of the fatigue stress range, the fatigue reliability can be evaluated with consideration of the service period of the bridge. In practice, the traffic volume and vehicle weight will increase with the development of the society economy. Suppose the annual linear growth rates of the GVW and ADTT are constants with a range of $0-0.5 \%$. On this basis, the fatigue reliability indices are shown in Figure 11, where 

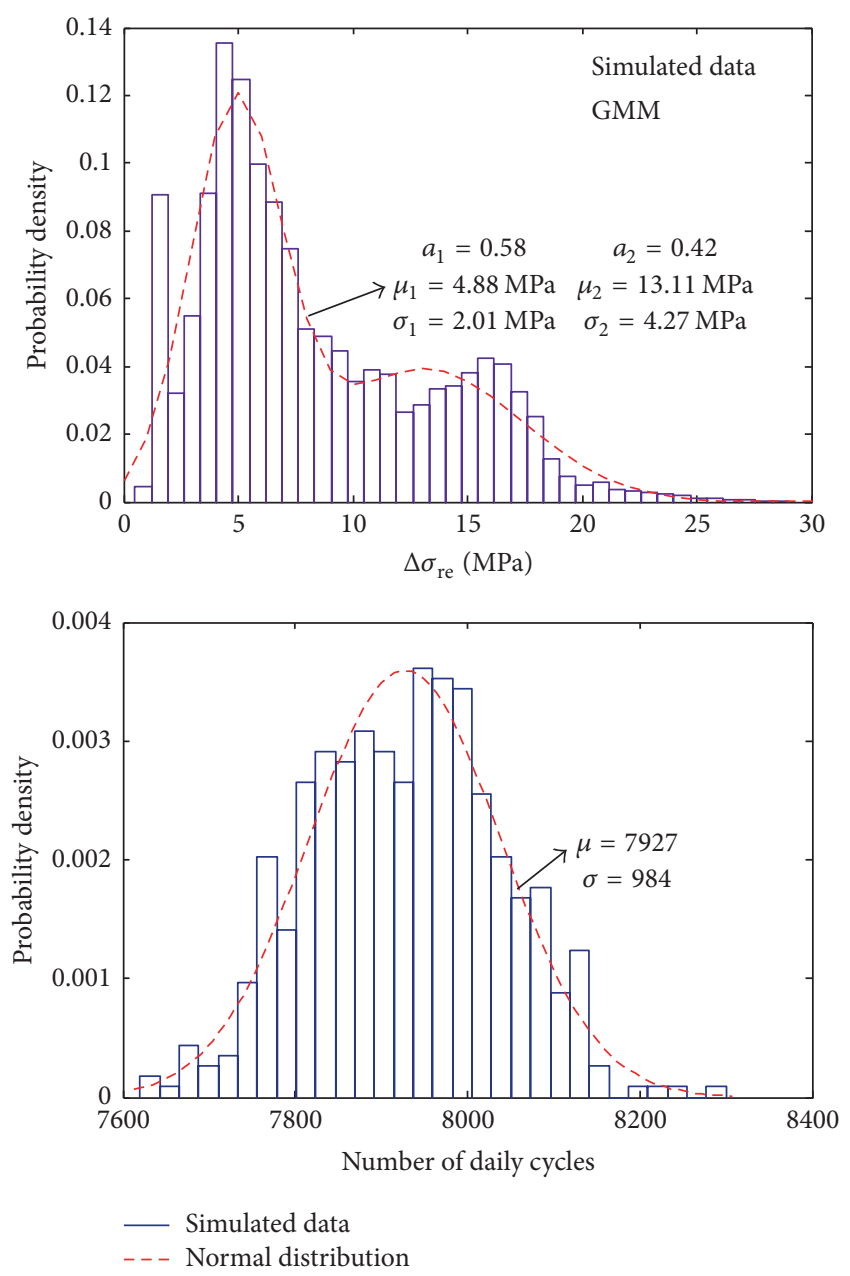

Figure 10: Probability density of the daily number of stress cycles.

$R_{1}$ indicates the growth rate of ADTT and $R_{2}$ indicates the growth rate of GVW.

It is observed from Figure 11 that both $R_{1}$ and $R_{2}$ lead to rapid decrease of the reliability index. Supposing the growth rate of both ADTT and GVW to be $0.5 \%$, the fatigue reliability index in the 100 years declines to 2.87 and 0.92 , respectively. These curves have demonstrated that the GVW growth results in a higher decrease of the reliability index compared to the ADTT growth. In practice, this phenomenon can be explained by the limit state function shown in (4) that the GVW has a 5-power impact to the fatigue damage. Obviously, truck overloading is the main reason resulting in the major fatigue damage of a bridge. Therefore, the control of overloaded trucks rather than the amount of traffic volume is an effective way to ensure the fatigue safety of the orthotropic steel bridge decks.

Since the overloaded trucks are the primary factor resulting in the fatigue failure of the orthotropic steel bridge deck, influence of the overload rate on the fatigue reliability deserves research. According to the Chinese specification [37], the threshold of the GVW for the 2-axle and the 6axle trucks is $200 \mathrm{kN}$ and $550 \mathrm{kN}$, respectively. In the present study, the threshold overload rate is assumed to be $25 \%$,

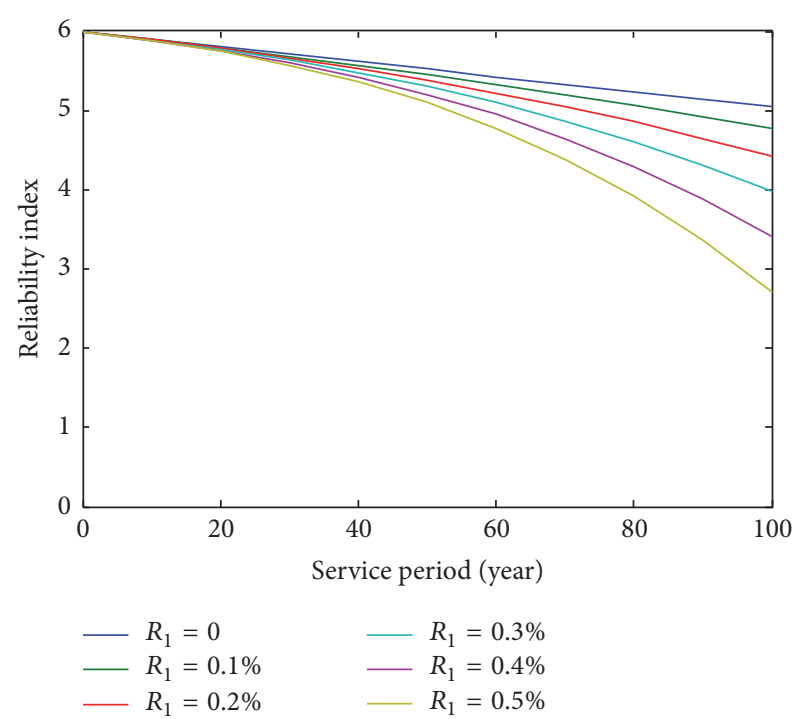

(a)

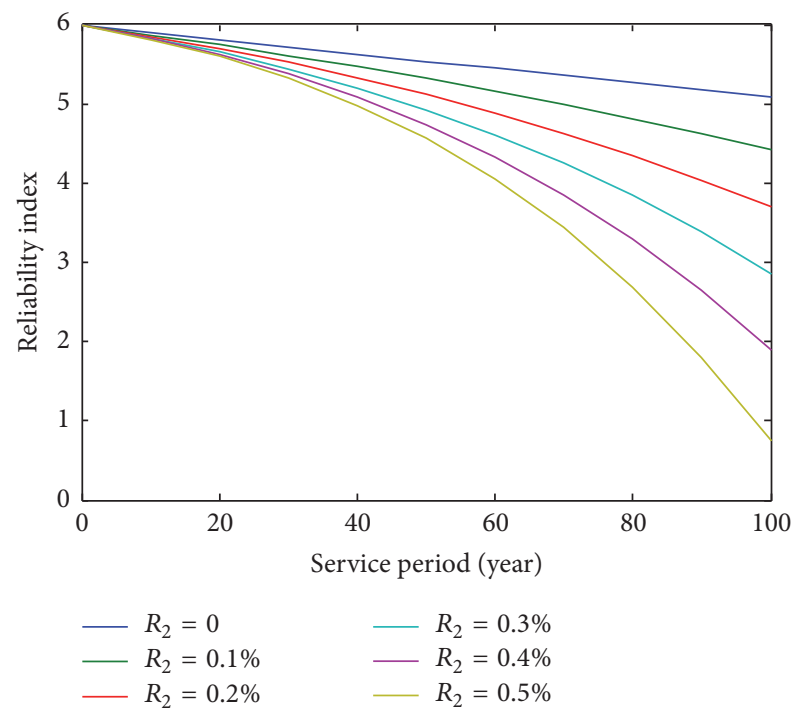

(b)

FIGURE 11: Fatigue reliability index of the rib-to-deck joint: (a) growth rate of ADTT and (b) growth rate of GVW.

$50 \%, 75 \%$, and $100 \%$. Based on the above assumption, the stochastic traffic flow load model was updated with the defined threshold overload rate. Influence of the threshold overload rate on the fatigue reliability of the rib-to-deck joint in the 100th year is shown in Figure 12.

It is observed from Figure 12 that the threshold overload rate has an effective impact on the fatigue reliability index. Even for a threshold of $100 \%$, the fatigue reliability index has an obvious increase. However, the spacing among these curves is reduced with the decrease of the threshold overload rate. This indicates that the influence of the ADTT growth on the reliability index weakens under a strict overload control measure. In addition to the increase of reliability index, the threshold overload rate has reduced the reliability index decline caused by the ADTT growth. This result suggests that 


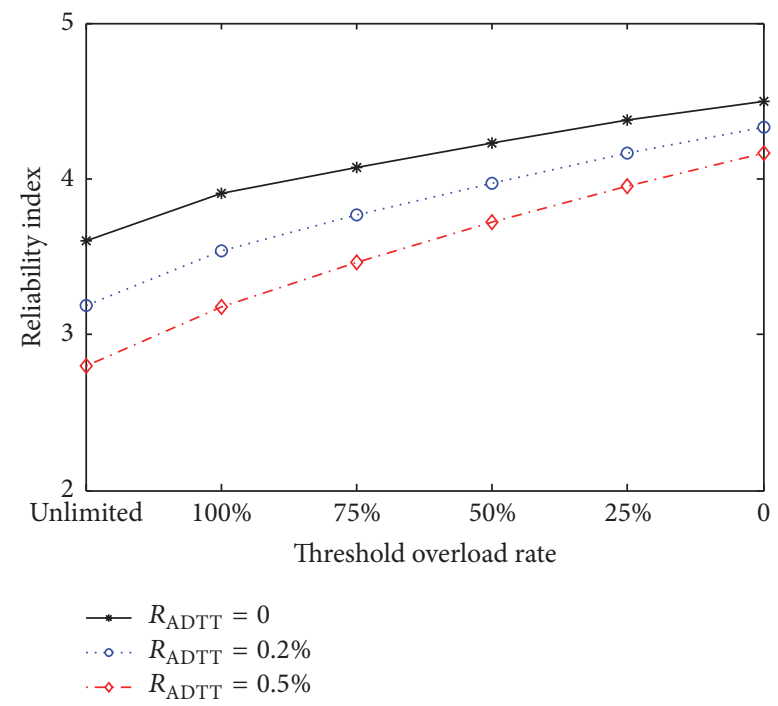

FigURE 12: Influence of the threshold overload rate on the fatigue reliably index.

even though the traffic volume growth is rapid, the control of overloaded truck is an effective way to ensure the fatigue reliability of steel bridges.

\section{Conclusions}

This study developed a stochastic fatigue truck model based on site-specific WIM measurements to evaluate fatigue reliability of orthotropic steel bridge decks. The time-consuming problem of the finite element-based hotspot stress simulation was solved by utilizing a response surface method. The effectiveness of the stochastic fatigue truck model in probabilistic modeling and fatigue reliability assessment was demonstrated by the case study of a segmental steel boxgirder bridge. Numerical results indicate that the growth rate of the GVW leads to a rapid decrease of the reliability index compared to the reliability index decrease caused by the ADTT growth. The threshold overload rate reduces the descending range of reliability index caused by the ADTT growth. In addition, even though the traffic volume growth is rapid, the control of overloaded trucks in comparison to the traffic volume is an effective way to ensure the fatigue safety of the steel bridges.

Future effort is needed to improve the stochastic fatigue truck-load model by considering the vehicle spacing parameter. The vehicle-bridge interaction and the degeneration of road surface roughness condition will be considered in the computational framework. Furthermore, uncertainties in the structural geometric dimensions and material properties will also be considered in the future work.

\section{Competing Interests}

The authors declare that they have no competing interests.

\section{Acknowledgments}

The authors would like to express their gratitude to the National Basic Research Program (973 Program) of China (no. 2015CB057705), the National Science Foundation of China (no. 51378081), and the Key Research Program in Civil Engineering from Changsha University of Science and Technology (15ZDXK06).

\section{References}

[1] The Committee on Fatigue and Fracture Reliability of the Committee on Structural Safety and Reliability of the Structural Division of ASCE, "Fatigue reliability: introduction," Journal of Structural Division, vol. 108, pp. 3-88, 1982.

[2] E. Poveda, R. C. Yu, J. C. Lancha, and G. Ruiz, "A numerical study on the fatigue life design of concrete slabs for railway tracks," Engineering Structures, vol. 100, pp. 455-467, 2015.

[3] W. Wang, L. Deng, and X. Shao, "Number of stress cycles for fatigue design of simply-supported steel I-girder bridges considering the dynamic effect of vehicle loading," Engineering Structures, vol. 110, pp. 70-78, 2016.

[4] S.-S. Cao and J.-Q. Lei, "Hybrid reliability model for fatigue reliability analysis of steel bridges," Journal of Central South University, vol. 23, no. 2, pp. 449-460, 2016.

[5] D. Rys, J. Judycki, and P. Jaskula, "Analysis of effect of overloaded vehicles on fatigue life of flexible pavements based on weigh in motion (WIM) data," International Journal of Pavement Engineering, vol. 17, no. 8, pp. 716-726, 2016.

[6] W. Wang, L. Deng, and X. Shao, "Fatigue design of steel bridges considering the effect of dynamic vehicle loading and overloaded trucks," Journal of Bridge Engineering, vol. 21, no. 9, 2016.

[7] T. Guo and Y.-W. Chen, "Fatigue reliability analysis of steel bridge details based on field-monitored data and linear elastic fracture mechanics," Structure and Infrastructure Engineering, vol. 9, no. 5, pp. 496-505, 2013.

[8] M. Saberi, A. Rahai, M. Sanayei, and R. Vogel, "Bridge fatigue service-life estimation using operational strain measurements," Journal of Bridge Engineering, vol. 21, no. 5, 2016.

[9] M. Liu, D. M. Frangopol, and K. Kwon, "Fatigue reliability assessment of retrofitted steel bridges integrating monitored data," Structural Safety, vol. 32, no. 1, pp. 77-89, 2010.

[10] M. Soriano, J. R. Casas, and M. Ghosn, "Simplified probabilistic model for maximum traffic load from weigh-in-motion data," Structure and Infrastructure Engineering, 2016.

[11] Y. Wang, Z. X. Li, and A. Q. Li, "Combined use of SHMS and finite element strain data for assessing the fatigue reliability index of girder components in long-span cable-stayed bridge," Theoretical and Applied Fracture Mechanics, vol. 54, no. 2, pp. 127-136, 2010.

[12] T. Guo, D. M. Frangopol, and Y. Chen, "Fatigue reliability assessment of steel bridge details integrating weigh-in-motion data and probabilistic finite element analysis," Computers and Structures, vol. 112-113, pp. 245-257, 2012.

[13] W. Zhang, C. S. Cai, and F. Pan, "Finite element modeling of bridges with equivalent orthotropic material method for multiscale dynamic loads," Engineering Structures, vol. 54, pp. 82-93, 2013.

[14] X. W. Ye, T.-H. Yi, C. Wen, and Y. H. Su, "Reliability-based assessment of steel bridge deck using a mesh-insensitive structural stress method," Smart Structures and Systems, vol. 16, no. 2, pp. 367-382, 2015. 
[15] J. Zhang and F. Au, "Fatigue reliability assessment considering traffic flow variation based on weigh-in-motion data," Advances in Structural Engineering, 2016.

[16] A. F. Hobbacher, S. J. Hicks, M. Karpenko, F. Thole, and B. Uy, "Transfer of Australasian bridge design to fatigue verification system of Eurocode 3," Journal of Constructional Steel Research, vol. 122, pp. 532-542, 2016.

[17] J. A. Laman and A. S. Nowak, "Fatigue-load models for girder bridges," Journal of Structural Engineering, vol. 122, no. 7, pp. 726-733, 1996.

[18] P. Chotickai and M. D. Bowman, "Truck models for improved fatigue life predictions of steel bridges," Journal of Bridge Engineering, vol. 11, no. 1, pp. 71-80, 2006.

[19] C. Lan, H. Li, and J. Ou, "Traffic load modelling based on structural health monitoring data," Structure and Infrastructure Engineering, vol. 7, no. 5, pp. 379-386, 2011.

[20] B. Chen, X. Li, X. Xie, Z. Zhong, and P. Lu, "Fatigue performance assessment of composite arch bridge suspenders based on actual vehicle loads," Shock and Vibration, vol. 2015, Article ID 659092, 13 pages, 2015.

[21] W. Zhang and C. S. Cai, "Fatigue reliability assessment for existing bridges considering vehicle speed and road surface conditions," Journal of Bridge Engineering, vol. 17, no. 3, pp. 443453, 2012.

[22] M. Zhang, Y. Li, and B. Wang, "Effects of fundamental factors on coupled vibration of wind-rail vehicle-bridge system for longspan cable-stayed bridge," Journal of Central South University, vol. 23, no. 5, pp. 1264-1272, 2016.

[23] Y. Zhou and S. Chen, "Numerical investigation of cable breakage events on long-span cable-stayed bridges under stochastic traffic and wind," Engineering Structures, vol. 105, pp. 299-315, 2015.

[24] Y. Liu, Y. Deng, and C. S. Cai, "Deflection monitoring and assessment for a suspension bridge using a connected pipe system: a case study in China," Structural Control and Health Monitoring, vol. 22, no. 12, pp. 1408-1425, 2015.

[25] N. Lu, M. Noori, and Y. Liu, "Fatigue reliability assessment of welded steel bridge decks under stochastic truck loads via machine learning," Journal of Bridge Engineering, 2016.

[26] D. Ngoduy and R. E. Wilson, "Multianticipative nonlocal macroscopic traffic model," Computer-Aided Civil and Infrastructure Engineering, vol. 29, no. 4, pp. 248-263, 2014.

[27] H.-B. Sim and C.-M. Uang, "Stress analyses and parametric study on full-scale fatigue tests of rib-to-deck welded joints in steel orthotropic decks," Journal of Bridge Engineering, vol. 17, no. 5, pp. 765-773, 2012.

[28] J.-H. Choi and D.-H. Kim, "Stress characteristics and fatigue crack behaviour of the longitudinal rib-to-cross beam joints in an orthotropic steel deck," Advances in Structural Engineering, vol. 11, no. 2, pp. 189-198, 2008.

[29] S. Ya, K. Yamada, and T. Ishikawa, "Fatigue evaluation of rib-todeck welded joints of orthotropic steel bridge deck," Journal of Bridge Engineering, vol. 16, no. 4, pp. 492-499, 2011.

[30] European Committee for Standardization (ECS), Design of Steel Structures, Part 1.1, Eurocode 3, Brussels, Belgium, 1993.

[31] M. Miner, "Cumulative damage in fatigue," Journal of Applied Mechanics, vol. 12, no. 3, pp. 159-164, 1945.

[32] J. Zhu, C. Chen, and Q. Han, "Vehicle-bridge coupling vibration analysis based fatigue reliability prediction of prestressed concrete highway bridges," Structural Engineering and Mechanics, vol. 49, no. 2, pp. 203-223, 2014.
[33] J. Cheng, Q. S. Li, and R.-C. Xiao, "A new artificial neural network-based response surface method for structural reliability analysis," Probabilistic Engineering Mechanics, vol. 23, no. 1, pp. 51-63, 2008.

[34] Y. Liu, N. Lu, M. Noori, and X. Yin, "System reliability-based optimisation for truss structures using genetic algorithm and neural network," International Journal of Reliability and Safety, vol. 8, no. 1, pp. 51-69, 2014.

[35] A. Q. Li, Y. L. Ding, H. Wang, and T. Guo, "Analysis and assessment of bridge health monitoring mass data-progress in research/development of 'structural Health Monitoring"' Science China Technological Sciences, vol. 55, no. 8, pp. 2212-2224, 2012.

[36] P. H. Wirsching, "Fatigue reliability for offshore structures," Journal of Structural Engineering, vol. 110, no. 10, pp. 2340-2356, 1984.

[37] Ministry of Communications and Transportation, "Limits of dimensions, axle load and masses for road vehicles," Tech. Rep. GB 1589-2004, China Communications Press, Beijing, China, 2004. 


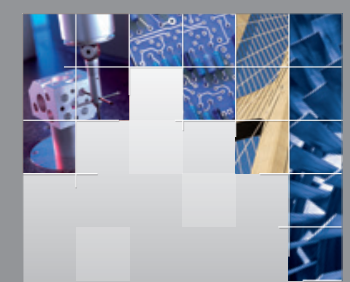

\section{Enfincering}
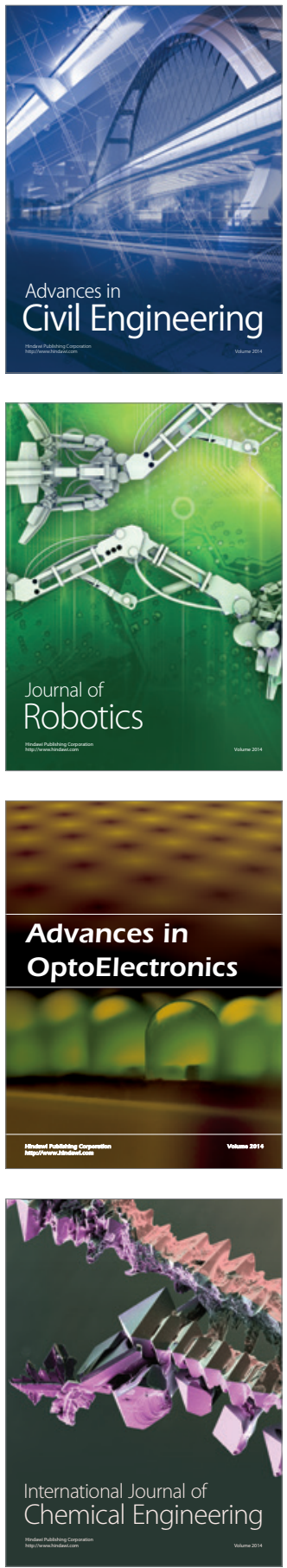

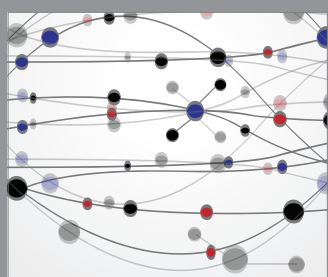

The Scientific World Journal

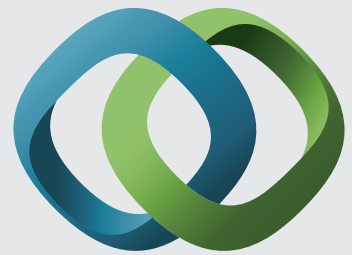

\section{Hindawi}

Submit your manuscripts at

http://www.hindawi.com
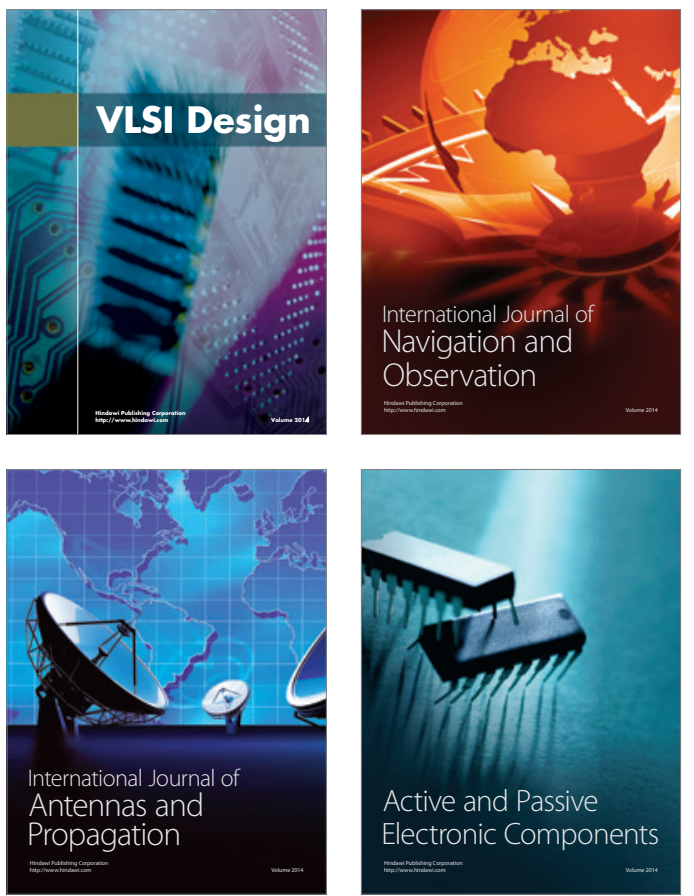
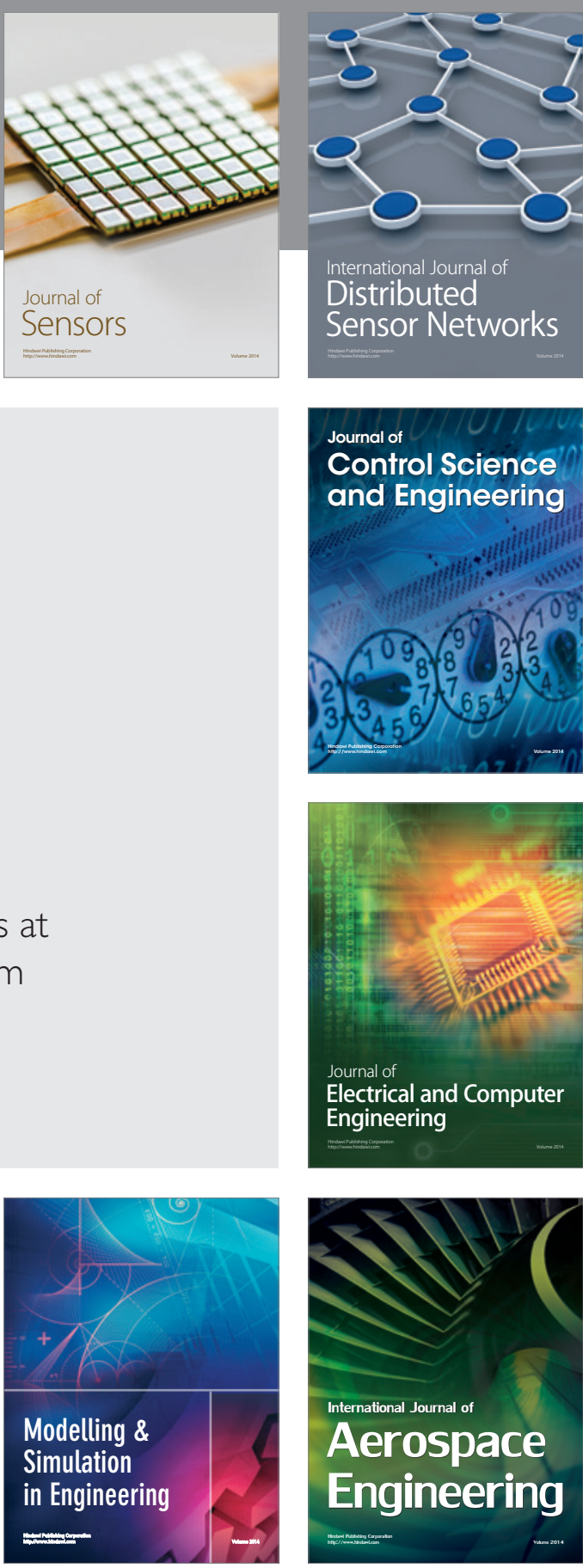

International Journal of

Distributed

Sensor Networks

Journal of

Control Science

and Engineering
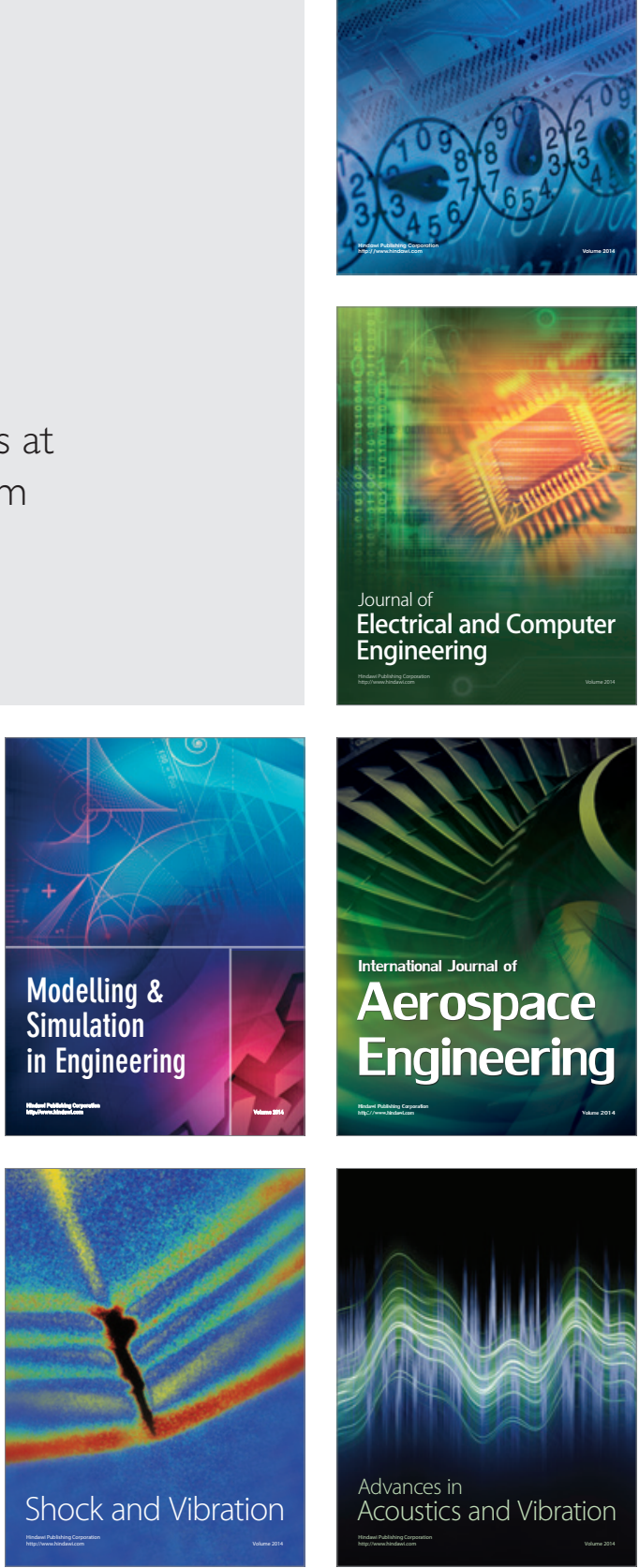